J. Dairy Sci. 99:8549-8560

http://dx.doi.org/10.3168/jds.2016-11284

(C) 2016, THE AUTHORS. Published by FASS and Elsevier Inc. on behalf

of the American Dairy Science Association ${ }^{\circledR}$. This is an open access article under

the CC BY-NC-ND license (http://creativecommons.org/licenses/by-nc-nd/3.0/).

\title{
Prediction of fat globule particle size in homogenized milk using Fourier transform mid-infrared spectra ${ }^{1}$
}

\author{
Larissa Di Marzo, ${ }^{*}$ Patrick Cree, $\dagger$ and David M. Barbano*2 \\ *Northeast Dairy Food Research Center, Department of Food Science, Cornell University, Ithaca, NY 14853 \\ †Delta Instruments, Kelvinlaan 3, 9207 Drachten, the Netherlands
}

\section{ABSTRACT}

Our objective was to develop partial least square models using data from Fourier transform mid-infrared (MIR) spectra to predict the particle size distributions $\mathrm{d}(0.5)$ and $\mathrm{d}(0.9)$, surface volume mean diameter $\mathrm{D}[3,2]$, and volume moment mean diameter $\mathrm{D}[4,3]$ of milk fat globules and validate the models. The goal of the study was to produce a method built into the MIR milk analyzer that could be used to warn the instrument operator that the homogenizer is near failure and needs to be replaced to ensure quality of results. Five homogenizers with different homogenization efficiency were used to homogenize pasteurized modified unhomogenized milks and farm raw bulk milks. Homogenized milks were collected from the homogenizer outlet and then run through an MIR milk analyzer without an in-line homogenizer to collect a MIR spectrum. A separate portion of each homogenized milk was analyzed with a laser light-scattering particle size analyzer to obtain reference values. The study was replicated 3 times with 3 independent sets of modified milks and bulk tank farm milks. Validation of the models was done with a set of 34 milks that were not used in the model development. Partial least square regression models were developed and validated for predicting the following milk fat globule particle size distribution parameters from MIR spectra: $\mathrm{d}(0.5)$ and $\mathrm{d}(0.9)$, surface volume mean diameter $\mathrm{D}[3,2]$, and volume moment mean diameter $\mathrm{D}[4,3]$. The basis for the ability to model particle size distribution of milk fat emulsions was hypothesized to be the result of the partial least square modeling detecting absorbance shifts in MIR spectra of milk fat due to the Christiansen effect. The independent sample validation of particle size prediction methods found

\footnotetext{
Received April 6, 2016.

Accepted June 17, 2016.

${ }^{1}$ Use of names, names of ingredients, and identification of specific models of equipment is for scientific clarity and does not constitute any endorsement of product by authors, Cornell University.

${ }^{2}$ Corresponding author: dmb37@cornell.edu
}

more variation in $\mathrm{d}(0.9)$ and $\mathrm{D}[4,3]$ predictions than the $\mathrm{d}(0.5)$ and $\mathrm{D}[3,2]$ predictions relative to laser lightscattering reference values, and this may be due to variation in particle size among different pump strokes. The accuracy of the $\mathrm{d}(0.9)$ prediction for routine quality assurance, to determine if a homogenizer within an MIR milk analyzer was near the failure level [i.e., d(0.9) $>1.7 \mu \mathrm{m}]$ and needed to be replaced, is fit-for-purpose. The daily average particle size performance [i.e., $\mathrm{d}(0.9)$ ] of a homogenizer based on the mean for the day could be used for monitoring homogenizer performance.

Key words: particle size, homogenization, midinfrared, light scattering

\section{INTRODUCTION}

Annually, in the United States, millions of kilograms of milk are produced and tested daily for the determination of the concentration of the main components (i.e., protein, fat, and other solids). The results are used by processors to determine the payment of dairy farmers, and by the farmers for dairy herd management (Lynch et al., 2004; Barbano and Lynch, 2006). Mid-infrared (MIR) milk analyzers have been used and have positively affected the dairy industry and farmers by providing rapid, cost effective, and direct determination of milk components (Barbano and Clark, 1989; Lynch et al., 2004, 2006; Adams and Barbano, 2015).

A laboratory homogenizer made it possible for homogenized emulsions to be analyzed by an MIR milk analyzer (Phipps 1960, 1975). Today, all MIR milk analyzers have an internal homogenizer that breaks the native fat globules to smaller sizes (Goulden, 1961; Biggs, 1967; Biggs et al., 1987). The main reason why fat globules need to be reduced to smaller sizes is that large fat globules increase light scattering, leading to an inaccurate estimate of fat, protein, and lactose content of milk (Barbano and Clark, 1989; Smith et al. 1993). Furthermore, large fat globules can also lead to the Christiansen light-scattering effect (Goulden, 1964; Smith et al., 1993), which causes a change of in the refraction of light at wavelengths near maximum ab- 
sorption by the carbonyl and carbon-hydrogen groups. The Christiansen effect causes a shift in the apparent wavelength of maximum light absorption to a longer wavelength. This effect can be reduced by decreasing the fat globule diameter. Ideally, after homogenization, the fat globule diameter of milk should be less than one-third of the wavelength of fat B $(3.48 \mu \mathrm{m})$, which is the shortest wavelength used for fat analysis (Goulden, 1964; Smith et al., 1993). Different types of homogenizers have different efficiency; at the same pressure, a single-stage homogenizer will be less efficient than a double stage homogenizer. Other factors that may affect homogenizer efficiency are milk temperature, pump speed, pump stroke length, fat content, and time of usage (Goulden and Phipps, 1964; Walstra and Jenness, 1984). The deterioration of a homogenizer's mechanical components over time may be difficult for the operator to detect and will have a negative effect on analytical repeatability and accuracy (Lynch et al., 2006).

Various tests to evaluate homogenizer efficiency have been used over the years. One test is called the recycle test, where an unhomogenized milk is run through an MIR milk analyzer, the readings are recorded, and the homogenized milk is collected from the instrument outlet tube. Next, the collected homogenized milk is rerun through the instrument and the readings are recorded. If the difference in readings for the fat test on the unhomogenized milk and the instrument homogenized milk is $<0.05 \%$, then the homogenizer meets minimum performance standards (AOAC International, 2000; International Dairy Federation, 2000). As the homogenizer performance decreases, the difference between the 2 results gets larger, but as the homogenizer performance continues to get worse across time, the difference in results becomes $<0.05 \%$ again. Thus, a homogenizer that does not homogenize at all or very poorly will pass the evaluation (Barbano and Clark, 1989; Smith et al., 1993; Lynch et al., 2006). Therefore, the recycle test is easy to preform but, because of this weakness, is not very good.

Another method to evaluate homogenizer efficiency is the determination of milk fat globule size distribution using a laser light scattering particle size analyzer after unhomogenized milk is homogenized through the MIR milk analyzer (Lynch et al., 2006). Laser light scattering uses Mie theory to calculate the particle size distribution, assuming a volume equivalent sphere model. Mie theory predicts scattering intensity as a function of the angle at which light is scattered at the point of interaction with a spherical particle (Horvath, 2009).

The milk fat globule diameter distribution reported by laser light-scattering particle size analyzers is based on the volume of the sphere (i.e., according to the volume of each fat globule present in the sample the instrument calculates a diameter). The parameter reported as particle size distribution $\mathbf{d}(\mathbf{0 . 5})$ is the median of volume distribution [i.e., half of the total fat globules volume in the sample comes from particles with diameter smaller than the $d(0.5)$ value and half of the total fat globules volume in the sample comes from particles with diameter larger than the $\mathrm{d}(0.5)$ value]. The parameter reported as particle size distribution $\mathbf{d}(\mathbf{0 . 9})$ indicates that $90 \%$ of the total fat globules volume in the sample comes from particles with diameter that lies below the $\mathrm{d}(0.9)$. The surface volume mean diameter $\mathbf{D}[\mathbf{3 , 2}]$ and volume moment mean diameter $\mathbf{D}[4,3]$ are calculated from the particle size distribution (Allen, 1990). The surface volume mean diameter $\mathrm{D}[3,2]$, also known as Sauter mean diameter, is calculated using the equation $\mathrm{x}_{\mathrm{SV}}=\Sigma \mathrm{x}^{3} \mathrm{dN} / \Sigma \mathrm{x}^{2} \mathrm{dN}$, where $\mathrm{x}=$ average particle diameter lying in the size range $x_{i}$ to $x_{n}(\mu m)$ and $d N=$ the percentage of the total number of particles lying in the size range $x_{i}$ to $x_{n}$. The volume moment mean diameter $\mathrm{D}[4,3]$, also known as De Broucker mean diameter, is calculated using the equation $\mathrm{x}_{\mathrm{VM}}=\Sigma \mathrm{x}^{4} \mathrm{dN} / \Sigma \mathrm{x}^{3} \mathrm{dN}$, where $\mathrm{x}=$ average particle diameter lying in the size range $x_{i}$ to $x_{n}(\mu \mathrm{m})$ and $d N=$ the percentage of the total number of particles lying in the size range $x_{i}$ to $x_{n}$.

Particle size of the milk produced by a homogenizer within an MIR should result in a mean globule diameter $\mathrm{d}(0.9)<1.7 \mu \mathrm{m}$; if $\mathrm{d}(0.9) \geq 1.7 \mu \mathrm{m}$, then the homogenizer performance has deteriorated and should be replaced (Smith et al., 1995; Lynch et al., 2006). Our objective was to develop models using data from Fourier transform MIR spectra to predict the particle size distributions $\mathrm{d}(0.5)$ and $\mathrm{d}(0.9)$, surface volume mean diameter $\mathrm{D}[3,2]$, and volume moment mean diameter $\mathrm{D}[4,3]$ of milk fat globules and validate the partial least square (PLS) model performance. The goal of the study was to produce a method built into the MIR milk analyzer that could be used to warn the instrument operator that the homogenizer is near failure and needs to be replaced to ensure quality of results.

\section{MATERIALS AND METHODS}

\section{Experimental Design}

Five different homogenizers with different homogenization efficiency (i.e., produced different milk globule size distributions) were used to homogenize 2 types of milk samples sets. The first type of milk sample set contained 12 pasteurized, preserved, modified, and unhomogenized milks ranging from 1.0 to $5.7 \%$ fat, as described by Kaylegian et al. (2006), and the second set contained 12 different preserved raw bulk milks obtained from the USDA Federal Milk Market Laboratory (Cleveland, $\mathrm{OH}$ ) that ranged in fat from about 2.6 
to $5.6 \%$. All milks were preserved with bronopol (Microtabs II, Advanced Instruments, Norwood, MA) at $0.01 \%$ by mass concentration as described by Barbano et al. (2010).

Milks were run through each homogenizer at 40 to $42^{\circ} \mathrm{C}$. Two different pumping systems were used, one for homogenizers from Delta Instruments HomoScope (model HU-3.0, Delta Instruments, Drachten, the Netherlands) and a modified Milkoscan 104 pumping system for homogenizers from Foss Electric (Hillerød, Denmark). All homogenized milks were collected from the homogenizer outlet and then pumped through a MIR milk analyzer without an in-line homogenizer [LactoScope FTIR Advanced (FTA), Delta Instruments]. The in-line homogenizer was replaced with a reverse inlet valve in the flow system of a Delta Instruments model FTA and an MIR spectrum was collected for every homogenized milk. Separate portions of the same homogenized milks were analyzed with a particle size analyzer (Mastersizer 2000, model MS2000; Malvern Instruments, Worcestershire, UK). The study was replicated 3 times with 3 independent sets of modified milks and bulk tank farm milks. The spectra from the total population of milks were analyzed using PLS regression analysis with Grams A/I PLSIQ Version 7.00 software (Thermo Fisher Scientific Inc., Waltham, MA) to develop PLS prediction models for particle size distributions $\mathrm{d}(0.5)$ and $\mathrm{d}(0.9)$, surface volume mean diameter $\mathrm{D}[3,2]$, and volume moment mean diameter $\mathrm{D}[4,3]$ of milk fat globules in homogenized milks. The PLS models were developed in 2 steps: (1) prediction model development, where the relationship between the MIR absorbance spectra and response $[\mathrm{d}(0.5), \mathrm{d}(0.9)$, $\mathrm{D}[3,2]$, and $\mathrm{D}[4,3]]$ was estimated from the set of reference samples; and (2) external sample validation, where the prediction model was used to predict the particle size of each unknown milk from the sample spectra in comparison to laser light-scattering reference test values on each milk (Haaland and Thomas, 1988). The external validation of the accuracy of the PLS models was determined using a set of 34 bulk tank milks that were not part of the population of milks used to develop the PLS prediction models.

\section{Homogenizers Used in the Study}

One 2-stage homogenizer (Foss Electric) was connected to a modified MilkoScan model 104 (Foss Electric). Four different 2-stage Delta Instruments homogenizers were connected to a Delta HomoScope (model HU-3.0, Delta Instruments). The homogenization systems were not attached to an infrared milk analyzer and were designed only to produce a population of milks with a wide range of milk fat globule diameters for the purpose of prediction model development. Homogenizers with different homogenization performances were selected to produce a wide range of particle size distributions that might be encountered when the performance of a homogenizer within an MIR milk analyzer deteriorates.

\section{Homogenization of Milks}

On each test day, a water bath (model 406015, AO Scientific Instruments, Division of Warner-Lambert Technologies, Keene, NH) was used to heat water to 41 to $43^{\circ} \mathrm{C}$. An Erlenmeyer flask containing $0.01 \%$ (vol/ vol) Triton-X 100 surfactant solution (G000071020, Delta Instruments) and $0.5 \%$ (wt/vol) nonfoaming Stella anionic cleaning solution (336446, Foss Electric) as well as 2 homogenizers were all placed in the water bath. The homogenizers were tempered to $42^{\circ} \mathrm{C}$ so they would quickly come to temperature equilibrium when attached to the pumping system. The first 6 milk samples were placed in the water bath and warmed to $42^{\circ} \mathrm{C}$, whereas the other milk samples were placed in a bin containing crushed ice and were placed into the water bath one at a time as soon as another sample was taken out to be homogenized. The first milk was mixed by inversion, the temperature was checked, and the milk was run through the homogenizer and collected at the outlet in a clear 90-mL vial (CPP03EDM-CL, Capitol Plastic Products, Amsterdam, NY). The collected homogenized milk was mixed by inversion and a portion was poured into a clear 15-mL vial (CPP500-Cornell, Capitol Plastic Products) and placed in crushed ice for rapid cooling and then refrigerated at $4^{\circ} \mathrm{C}$ for later analysis with laser light scattering. The homogenized milk left into the $90-\mathrm{mL}$ vial was analyzed using an MIR milk analyzer that did not contain a homogenizer in the flow system. This procedure was repeated for all samples of the 2 sets; in between each sample the homogenizer was flushed with distilled water at $42^{\circ} \mathrm{C}$. At the end of each run the homogenizer was cleaned by running $150 \mathrm{~mL}$ of reverse osmosis water, $150 \mathrm{~mL}$ of Stella, and $150 \mathrm{~mL}$ of Triton-X 100 solution, and then the homogenizer was detached from the pumping system. The next homogenizer that was in the water bath was connected to the pumping system and the procedure was repeated. The same unhomogenized milks were pumped through all 5 different homogenizers. The order in which the homogenizer heads were used to produce homogenized milks was different within each replicate.

With each of the 5 homogenizers, a set of 12 different modified milk (Kaylegian et al., 2006) samples, ranging from about 1.0 to $5.7 \%$ fat, were homogenized and a set of 12 individual producer bulk tank milks were homogenized to produce 120 homogenized milks. This was 
replicated 3 times in different weeks using a different set of modified milks and producer milks in each replicate to produce spectra from 360 homogenized milks for PLS model development.

\section{MIR Analysis}

Midinfrared analysis of the 360 homogenized milks described above was performed with the LactoScope FTIR Advanced (FTA) milk analyzer equipped with a BMX optical bench (ABB Bomem, Montreal, Canada). A $\mathrm{CaF}_{2}$ cuvette $(36 \mu \mathrm{m})$ was used for the analysis. For collection of the MIR spectra for milk samples, the LactoScope FTA was operated at a spectral resolution of 8 $\mathrm{cm}^{-1}$ (digital resolution of $3.85 \mathrm{~cm}^{-1}$ ), collecting averages of 16 scans per analysis (using standard double-sided forward-backward interferogram acquisition, cosine apodization, and phase correction for Fourier transformation yielding an energy spectrum). The average of 16 scans was transformed into an absorption spectrum by calculation of the $-\log$ ratio with reference to the spectrum of zero liquid (demineralized water containing $0.01 \%$ triton) and storing the absorption spectrum for milk. The instrument homogenizer was replaced with a reverse inlet valve that had exactly the same shape as an in-line homogenizer but did not contain balls, seats, or springs normally present in a working homogenizer. For collection of the MIR spectra for milk samples, the instrument was cleaned using Decon 90 (Decon Laboratories Ltd., East Sussex, UK). Spectra were collected for each milk using 3 pumping cycles to flush externally homogenized milk through the flow system with the reverse inlet valve and 3 measure cycles without pumping to collect spectra. The range of wave numbers in the spectra was from 400 to $4,000 \mathrm{~cm}^{-1}$. These spectra in combination with the Malvern Mastersizer 2000 reference particle size values were analyzed using the PLS routines of the Grams A/I PLSIQ Version 7.00 software (Thermo Fisher Scientific Inc.) to calculate the $\beta$ coefficients for PLS prediction models designed to predict fat globule size based on the MIR spectra. Data obtained by the MIR and particle size analysis were used to develop 4 PLS statistical models: particle size distributions $\mathrm{d}(0.5)$ and $\mathrm{d}(0.9)$, surface volume mean diameter $\mathrm{D}[3,2]$, and volume moment mean diameter $\mathrm{D}[4,3]$ of milk fat globules in homogenized milk.

\section{Particle Size Analysis}

Milks were analyzed using a Malvern Mastersizer 2000 (Malvern Instruments), software version 5.4. Milks at $42^{\circ} \mathrm{C}$ were dispersed in reverse osmosis water at $42^{\circ} \mathrm{C}$ to ensure that the milk fat was liquid and globules were spherical. The refractive index for the particles (i.e., milk fat) at $42^{\circ} \mathrm{C}$ was set at 1.458 and 1.33 for the suspending medium (water at $42^{\circ} \mathrm{C}$ ) for the red laser (forward light scattering). The particle size model was set as general purpose and particle shape was set to spherical. The measure time for sample and background was set at $5 \mathrm{~s}$ with 5,000 snaps. A light obscuration range limit was set to fall with a range of 7 to $9 \%$, with 3 measurement cycles per sample with zero time delay between measurements.

The Mastersizer 2000 has both a red (forward scatter for larger particles; e.g., fat globules) and a blue laser (side scattering for smaller particles; e.g., casein micelles). In our work, only the particle size distribution of the fat globules was of interest. To eliminate the contribution of casein micelles from the particle size distribution, the data kill function of the Mastersizer 2000 software was set to include only the particles in the size range from 0.195 to $18.32 \mu \mathrm{m}$. Whereas some small, naturally occurring fat droplets may be present in raw milk $<0.195 \mu \mathrm{m}$ in diameter that are not a product of homogenization, those fat droplets were not of interest and they have very little effect on the volume-based particle size distribution of fat. Most casein micelles are $<0.195 \mu \mathrm{m}$ in diameter, so using the data kill function was a practical way to exclude the contribution of the casein micelles. This approach was developed by comparing the particle size results from a Mastersizer E with the Mastersizer 2000 on the same homogenized and unhomogenized milk samples. The Mastersizer E has only a red laser and has no side scatter detectors.

Before each sample analysis, the flow system was rinsed with reverse osmosis water at $45^{\circ} \mathrm{C}$ and drained 3 times to ensure that the cell was warm, and then $45^{\circ} \mathrm{C}$ reverse osmosis water was added to fill the system and recirculated to remove air. The recirculation pump was set to $2,250 \mathrm{rpm}$. Vials of homogenized milks were heated to $42^{\circ} \mathrm{C}$ in a water bath (Narco, model 220-A, National Appliance Company, Portland, OR), mixed by inversion, and added to recirculating reverse osmosis water in the sample dispersion unit until the laser obscuration was in the range of 7 to $9 \%$; after that the analysis was started. Once all the samples were run, the system was rinsed 3 times with reverse osmosis water, 2\% Contrad-70 (Decon Laboratories Inc., King of Prussia, PA) solution was added to the dispersion unit and left for 15 min with the pump set to 1,750 rpm. Then, the solution was drained and the system was rinsed with $45^{\circ} \mathrm{C}$ reverse osmosis water until there was no more foam. The following measured parameters from Malvern Mastersizer 2000 were used: particle size distributions $\mathrm{d}(0.5)$ and $\mathrm{d}(0.9)$, surface volume mean diameter $\mathrm{D}[3,2]$, and volume moment mean diameter $\mathrm{D}[4,3]$ of milk fat globules in homogenized milk. 


\section{Development of the PLS Statistical Models}

Removal of Outliers. Of the total 360 modified milks and bulk tank farm milks, the data set for $\mathrm{d}(0.5)$ and $\mathrm{d}(0.9)$ model development had 11 and 3 milk samples removed, respectively, which were spectral outliers. The $\mathrm{D}[3,2]$ model had 12 spectral outliers removed, and the $\mathrm{D}[4,3]$ model had 16 spectral outliers removed during the iterative modeling process. Criteria for removal of outliers was based on Mahalanobis distances.

Calculation of PLS Models. The PLS models for prediction of $\mathrm{d}(0.5), \mathrm{d}(0.9), \mathrm{D}[3,2]$, and $\mathrm{D}[4,3]$ were calculated using spectral ranges of 3,000 to $2,750,1,800$ to 1,700 , and 1,585 to $1,000 \mathrm{~cm}^{-1}$. Data were not mean centered and a baseline correction was not used. Cross validation (cyclic leaving out 1 sample at a time) was applied for determining the number of factors used for each model. Spectral and concentration outlier samples were identified, removed from the data set, and then the PLS modeling was repeated with outliers removed. The number of factors selected for each final prediction model was the number of factors that produced an Ftest predicted residual sum of squares of approximately 0.57 , which will be near the minimum standard error of cross validation (SECV). Adding more factors to the model starts modeling in noise and may increase the SECV (Haaland and Thomas, 1988). The PLS prediction models were developed using the following equation $\mathrm{Y}=\beta_{0}+\beta_{1} \mathrm{X}_{1}+\ldots \beta_{\mathrm{k}} \mathrm{X}_{\mathrm{k}}+\mathrm{e}$, , where $\mathrm{Y}$ $=$ response [i.e., $\mathrm{d}(0.5), \mathrm{d}(0.9), \mathrm{D}[3,2]$, and $\mathrm{D}[4,3]$ values], $\mathrm{X}=$ MIR spectral absorbance, $\beta=\beta$ coefficients, and $\mathrm{e}=$ error term. The estimation of $\beta$ coefficients is based on the observed Y values and PLS scores for the optimum number of PLS factors and represents the correlation between $\mathrm{Y}$ and each of the $\mathrm{X}$ absorbances (Janik et al., 2007). The PLS models for $\mathrm{d}(0.5)$, $\mathrm{d}(0.9)$, $\mathrm{D}[3,2]$, and $\mathrm{D}[4,3]$ were developed and installed into the Delta Instruments FTIRScope Advanced software to enable the MIR to output particle size data directly for each milk tested.

\section{Performance of the PLS Models}

Slope and Intercept Adjustment. The PLS models for MIR prediction of $\mathrm{d}(0.5), \mathrm{d}(0.9), \mathrm{D}[3,2]$, and $\mathrm{D}[4,3]$ were slope and intercept adjusted using MIR calibration milks (samples 7 to 14 from modified milk sets). Three different homogenizers with different homogenization efficiency were used to homogenize each of the 8 modified milk samples. Each homogenizer was inserted in the Delta Instruments LactoScope FTIR Advanced (FTA) and each milk sample was analyzed 3 times to produce 3 MIR predictions of the 4 particle size param- eters for each milk. There are multiple pump strokes through the homogenizer in one milk analysis cycle of the instrument. The milk in the cuvette that is used for production of the spectra is the milk from a portion of one pump stroke (about $0.42 \mathrm{~g}$ ), whereas the milk collected from one pumping cycle for particle size analysis represents many pump strokes during that pumping cycle. Homogenization efficiency may vary slightly from one pump stroke to the next with the same milk. Milk from the second and third pumping or analysis cycle of each instrument homogenized milk was collected from the instrument's outlet tube and analyzed using the Malvern Mastersizer 2000 to produce particle size reference values $\mathrm{d}(0.5), \mathrm{d}(0.9), \mathrm{D}[3,2]$, and $\mathrm{D}[4,3]$ for each milk. The mean difference (MD), standard deviation of the difference (SDD), and relative standard deviation of the difference (i.e., coefficient of variation; RSD) were calculated for $\mathrm{d}(0.5), \mathrm{d}(0.9), \mathrm{D}[3,2]$, and $\mathrm{D}[4,3]$. A linear regression equation for each predicted particle size parameter was calculated by plotting reference values given by Malvern Mastersizer 2000 as a function of MIR predicted values (x-axis). These linear regression equations provided the slope and intercept adjustment of each predicted particle size parameter to achieve a mean difference between reference values and instrument predictions of zero.

External Sample Validation of the Models. After adjustment of slope and intercept, the performance of the PLS models for MIR prediction of $\mathrm{d}(0.5), \mathrm{d}(0.9)$, $\mathrm{D}[3,2]$, and $\mathrm{D}[4,3]$ was conducted with 34 individual farm bulk tank milks (12 from Cleveland, OH; 12 from Dallas, TX; and 10 from Lebanon, NH) that were not part of the population of milks used to develop the PLS prediction models. Three homogenizers with different homogenization efficiencies were used to homogenize each of the 34 milks, resulting in 102 samples to validate each PLS model. The homogenizers were connected in-line within the Delta Instruments LactoScope FTIR Advanced (FTA) and each sample was analyzed in triplicate (i.e., 3 pumping cycles). The instrument homogenized milk from the second and third pumping cycles was collected separately from the instrument's outlet tube and analyzed by the Malvern Mastersizer 2000 as described above. A value for each sample for the $\mathrm{d}(0.5), \mathrm{d}(0.9), \mathrm{D}[3,2]$, and $\mathrm{D}[4,3]$ milk fat globule was predicted by the MIR. The mean of reference values, mean of MIR predicted values, MD between MIR predicted and reference values, SDD, and RSD were calculated for the $\mathrm{d}(0.5), \mathrm{d}(0.9), \mathrm{D}[3,2]$, and $\mathrm{D}[4,3]$ PLS models. To determine if the mean of the reference values was different from the mean of the instrument predicted values a $t$-test was performed using SAS (SAS ver. 8.02, SAS Institute Inc., Cary, NC). 


\section{RESULTS}

\section{PLS Models for Prediction of d(0.5), d(0.9), $D[3,2]$, and $D[4,3]$}

The number of samples, mean of Malvern Mastersizer 2000 reference values, standard deviation, and minimum and maximum values used for development of each model are shown in Table 1 . The range of $d(0.9)$ values and the corresponding related particle size parameters used for the modeling (Table 1) covered the critical range of $\mathrm{d}(0.9)$ values $(1.0-3.4 \mu \mathrm{m})$ that need to be measured to determine if a homogenizer within an infrared milk analyzer has adequate performance to ensure repeatable and accurate data for other milk components measured by a MIR milk analyzer. New homogenizers are expected to produce a d(0.9) of milk homogenized at $40^{\circ} \mathrm{C}$ of $\leq 1.5 \mu \mathrm{m}$. A 12 -factor model was selected as the optimum model for prediction of $\mathrm{d}(0.5)$ and $\mathrm{D}[3,2]$ and a 10-factor model was selected as the optimum model for prediction of $\mathrm{d}(0.9)$ and $\mathrm{D}[4,3]$ (Table 1). The SECV, $\mathrm{R}^{2}$, F-ratio predicted residual sum of squares, F-test predicted residual sum of squares, and residual prediction deviation (RPD) values (i.e., ratio of standard deviation of final population of reference samples, with outliers removed, used to develop PLS prediction models to standard error of cross validation) for each PLS model are shown in Table 1. The higher the RPD value, the greater the standard deviation of an accurate prediction of an unknown sample. If the SECV is large compared with the standard deviation, resulting in a small RPD, the PLS model is considered less robust. A RPD value between 2 and 5 indicates that the calibration may be useful for screening purposes (i.e., qualitative determination; Williams, 2010). The RPD and $\mathrm{R}^{2}$ for the $\mathrm{d}(0.5), \mathrm{d}(0.9)$ and $\mathrm{D}[3,2]$ models are near 3 and 0.9 , respectively, whereas the $\mathrm{D}[4,3]$ has a lower RPD and $\mathrm{R}^{2}$ (Table 1 ).

The optimized MIR sample and reference center wavenumbers for fat, protein, and lactose measurements in milk were 2,851 and $2,812 \mathrm{~cm}^{-1}$ (fat B - symmetrical carbon hydrogen stretch); 1,748 and 1,791 $\mathrm{cm}^{-1}$ (fat A - carbonyl stretch); 1,541 and $1,491 \mathrm{~cm}^{-1}$ (protein - amide stretch); and 1,048 and $1,293 \mathrm{~cm}^{-1}$ (lactose - hydroxyl stretch), respectively (Kaylegian et al., 2009). For the development of PLS prediction models, 3 spectral regions were used: 3,000 to $2,750,1,800$ to 1,700 , and 1,585 to $1,000 \mathrm{~cm}^{-1}$. Beta coefficients for the PLS models for prediction of $\mathrm{d}(0.5), \mathrm{d}(0.9), \mathrm{D}[3,2]$, and $\mathrm{D}[4,3]$ were plotted as a function of wavenumber $\left(\mathrm{cm}^{-1}\right)$, as shown in Figures 1 and 2 . The $\beta$ coefficients for the $\mathrm{d}(0.5)$ and $\mathrm{D}[3,2]$ models are very similar in the wavenumber region between 3,000 to $2,750 \mathrm{~cm}^{-1}$ (Figure $1 \mathrm{~A}$ ) and between 1,800 to 1,700 and 1,585 to $1,000 \mathrm{~cm}^{-1}$
(Figure 2A). The $\beta$ coefficients for the $\mathrm{d}(0.9)$ and $\mathrm{D}[4,3]$ models have large values in the wavenumber regions between 3,000 to $2,750 \mathrm{~cm}^{-1}$ (Figure 1B), particularly at center wavelength $2,851 \mathrm{~cm}^{-1}$ used for the prediction of fat B (C-H stretch) content of milk; large values were also noted between 1,800 to 1,700 and 1,585 to 1,000 $\mathrm{cm}^{-1}$, particularly at $1,748 \mathrm{~cm}^{-1}$ used for the prediction of fat $\mathrm{A}(\mathrm{C}=\mathrm{O}$ stretch) content of milk (Figure $2 \mathrm{~B})$. The regions of the spectra where the $\beta$ coefficients are large are the areas that contain the most information to predict milk fat globule particle size distribution. This is consistent with the fact that poor homogenization performance within a MIR milk analyzer influences the accuracy of milk fat test.

\section{Performance of the MIR Particle Size Prediction Models}

Slope and Intercept Calibration Adjustment. A new PLS model prediction output starts with a secondary slope and intercept of 1 and 0 , respectively. Comparison of mean $\mathrm{d}(0.5), \mathrm{d}(0.9), \mathrm{D}[3,2]$, and $\mathrm{D}[4,3]$ reference values versus MIR-predicted values for milks 7 to 14 in the modified milk calibration set before and after slope and intercept adjustment are shown in Table 2 . After adjustment, the MD between reference and MIR was zero for all predicted parameters and the SDD and RSD of calibration adjustment are shown in Table 2 . The magnitude of the slope and intercept adjustment was the largest on the $\mathrm{d}(0.9)$ prediction. After adjustment, the RSD decreased from 8.8 to about $5.5 \%$. The prediction model for volume mean diameter $(\mathrm{D}[4,3])$ had the highest RSD.

Table 1. Number of samples, mean of reference values, SD, minimum, and maximum values of final population of samples (i.e., with outliers removed) used to develop partial least square (PLS) prediction models

\begin{tabular}{lcccc}
\hline & \multicolumn{4}{c}{ Mid-infrared PLS prediction models } \\
\cline { 2 - 5 } Item & $\mathrm{d}(0.5)$ & $\mathrm{d}(0.9)$ & $\mathrm{D}[3,2]$ & $\mathrm{D}[4,3]$ \\
\hline Number of samples & 349 & 357 & 348 & 344 \\
Mean $(\mu \mathrm{m})$ & 0.57 & 1.53 & 0.47 & 0.80 \\
SD $(\mu \mathrm{m})$ & 0.10 & 0.33 & 0.06 & 0.16 \\
Minimum ( $\mu \mathrm{m})$ & 0.32 & 1.03 & 0.34 & 0.50 \\
Maximum ( $\mu \mathrm{m})$ & 0.88 & 3.36 & 0.67 & 1.44 \\
Number of factors & 12 & 10 & 12 & 10 \\
SECV & 0.03 & 0.12 & 0.02 & 0.09 \\
R & 0.93 & 0.88 & 0.92 & 0.68 \\
F-Ratio (PRESS) & 1.03 & 1.01 & 1.03 & 1.01 \\
F-Test (FPRESS) & 0.60 & 0.54 & 0.61 & 0.53 \\
RPD & 3.73 & 2.83 & 3.44 & 1.75 \\
\hline
\end{tabular}

${ }^{1}$ Number of factors, standard error of cross validation (SECV), $\mathrm{R}^{2}$, F-ratio predicted residual sum of squares (PRESS), F-test (FPRESS), and ratio of standard deviation to standard error of cross validation (RPD) of the calibration step for the PLS model to predict particle size distributions $\mathrm{d}(0.5)$ and $\mathrm{d}(0.9)$, surface volume mean diameter $\mathrm{D}[3,2]$, and volume moment mean diameter $\mathrm{D}[4,3]$ from the mid-infrared spectra of homogenized milk samples. 
Validation of the Models. The slope and intercept adjustments (Table 2) were applied to the MIRpredicted values for the independent validation samples to determine the performance of the MIR particle size prediction models. The comparison of the $\mathrm{d}(0.5)$, $\mathrm{d}(0.9), \mathrm{D}[3,2]$, and $\mathrm{D}[4,3]$ reference values versus MIRpredicted values are shown in Table 3. For real-time evaluation of homogenizer performance in a MIR milk analyzer, the prediction of $\mathrm{d}(0.9)$ is the most important parameter related to analytical performance of the MIR milk analyzer (Lynch et al., 2006).

We found good agreement on average of laser lightscattering particle size reference values and MIR estimates of the 4 particle size distribution parameters (Table 3). The mean MIR-predicted values for $\mathrm{d}(0.5)$,
$\mathrm{D}[3,2]$, and $\mathrm{D}[4,3]$ were lower $(P<0.05)$ than laser light-scattering values, whereas no difference in the MIR-predicted $\mathrm{d}(0.9)$ versus laser light scattering was detected. All mean differences were small (i.e., 0.03 $\mu \mathrm{m})$. The RSD for the predictions of $\mathrm{d}(0.9)$ and $\mathrm{D}[4,3]$ were larger than for the $\mathrm{d}(0.5)$ and $\mathrm{D}[3,2]$, indicating more sample-to-sample analytical variation.

\section{DISCUSSION}

\section{What Did the PLS Modeling See in the Spectra to Model Particle Size?}

The $\beta$ coefficient plots contain the spectral information that drives the PLS model predictions and indi-
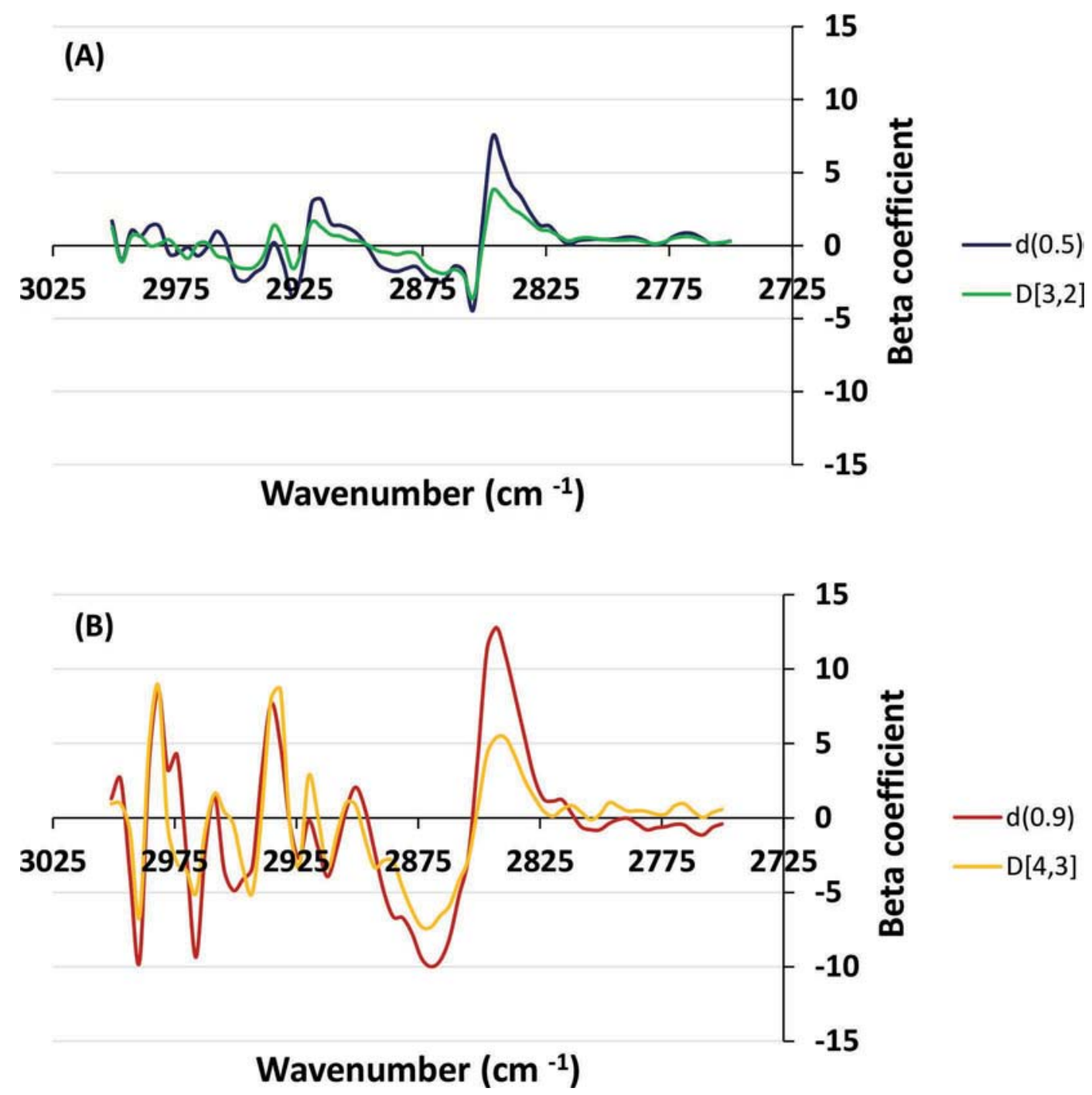

Figure 1. Beta coefficient plotted as a function of wavenumber $\left(\mathrm{cm}^{-1}\right)$ in spectral region of 3,000 to $2,750 \mathrm{~cm}^{-1}$ for the partial least squares prediction models: (A) particle size distribution $\mathrm{d}(0.5)$ and surface volume mean diameter $\mathrm{D}[3,2]$, and (B) particle size distribution $\mathrm{d}(0.9)$ and volume moment mean diameter $\mathrm{D}[4,3]$ of milk fat globules in homogenized milk. Color version available online. 

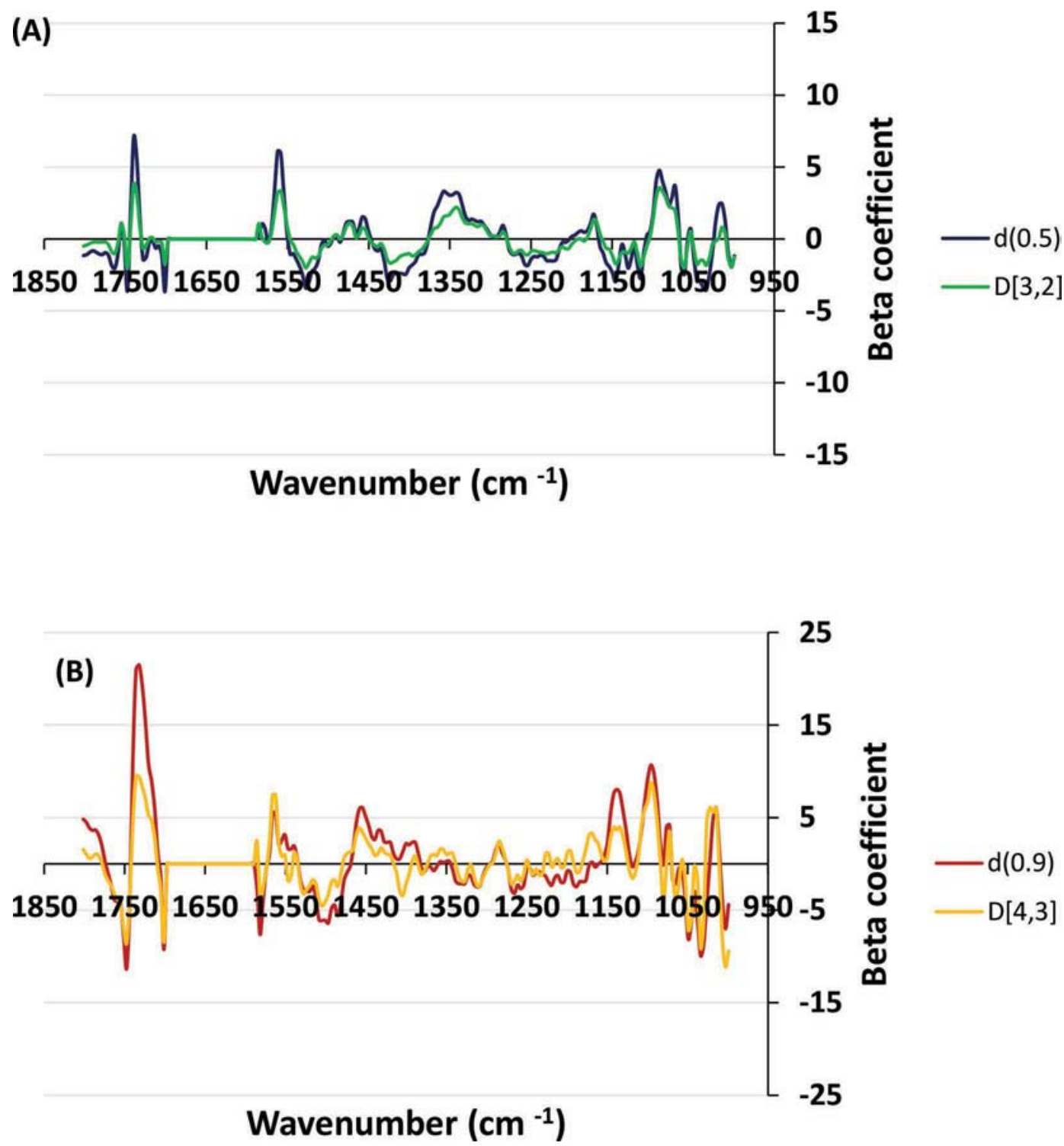

Figure 2. Beta coefficient plotted as a function of wavenumber $\left(\mathrm{cm}^{-1}\right)$ in spectral region of 1,800 to $1,700 \mathrm{~cm}^{-1}$ and 1,585 to $1,000 \mathrm{~cm}^{-1}$ for the partial least squares prediction models: (A) particle size distribution $\mathrm{d}(0.5)$ and surface volume mean diameter $\mathrm{D}[3,2]$, and (B) particle size distribution $\mathrm{d}(0.9)$ and volume moment mean diameter $\mathrm{D}[4,3]$ of milk fat globules in homogenized milk. Color version available online.

cates the correlation between the response $\mathrm{Y}[\mathrm{d}(0.5)$, $\mathrm{d}(0.9), \mathrm{D}[3,2]$, and $\mathrm{D}[4,3]$ values] and each of the $\mathrm{X}$ absorbance (i.e., indicate which $\mathrm{X}$ absorbance are contributing to the modeling of the response Y; Janik et al., 2007). Large $\beta$ coefficients in the wavenumber region between 2,855 to $2,845 \mathrm{~cm}^{-1}$ (Figure $1 \mathrm{~B}$ ) and between 1,740 to $1,710 \mathrm{~cm}^{-1}$ (Figure 2B) for the $\mathrm{d}(0.9)$ and $\mathrm{D}[4,3]$ models indicate a strong correlation between the infrared light absorbance present in those regions of the MIR spectra and the estimate of $\mathrm{d}(0.9)$ and $\mathrm{D}[4,3]$. To determine what was happening in those regions of the spectra, MIR absorbance spectra were plotted as a function of wavenumber $\left(\mathrm{cm}^{-1}\right)$ for sample $12(5 \%$ fat and $2.4 \%$ true protein) of the modified milk set, replicate 1 , homogenized using 5 different homogenizers to produce milk with different particle size distributions $\mathrm{d}(0.5)$ and $\mathrm{d}(0.9)$ in spectral regions 3,000 to 2,750 (Figure 3) and 1,800 to $1,700 \mathrm{~cm}^{-1}$ (Figure 4). Spectra of other samples exhibited similar behavior. At low magnification we found nothing outstanding in the MIR absorbance spectra in the wavenumber regions 3,000 to 2,750 (Figure $3 \mathrm{~A}$ ) and 1,800 to $1,700 \mathrm{~cm}^{-1}$ (Figure 4A), but when we zoom in the regions of absorbance between 2,860 to 2,850 (Figure 3B), and 1,750 to $1,740 \mathrm{~cm}^{-1}$ (Figure 4B) we observed a systematic shift in the region of absorbance of fat $\mathrm{B}$ and fat $\mathrm{A}$, respec- 
Table 2. Comparison of slope, intercept, $\mathrm{R}^{2}$, mean of reference values, mean of mid-infrared (MIR) predicted values, mean difference (MD) between MIR predicted and reference values, standard deviation of the difference (SDD), and relative standard deviation (RSD) of modified milk calibration set (samples 7-14) used as the calibration set for the partial least square models to predict particle size distributions $\mathrm{d}(0.5)$ and $\mathrm{d}(0.9)$, surface volume mean diameter $\mathrm{D}[3,2]$, and volume moment mean diameter $\mathrm{D}[4,3]$ from the MIR spectra of homogenized milk samples, before and after slope and intercept adjustment

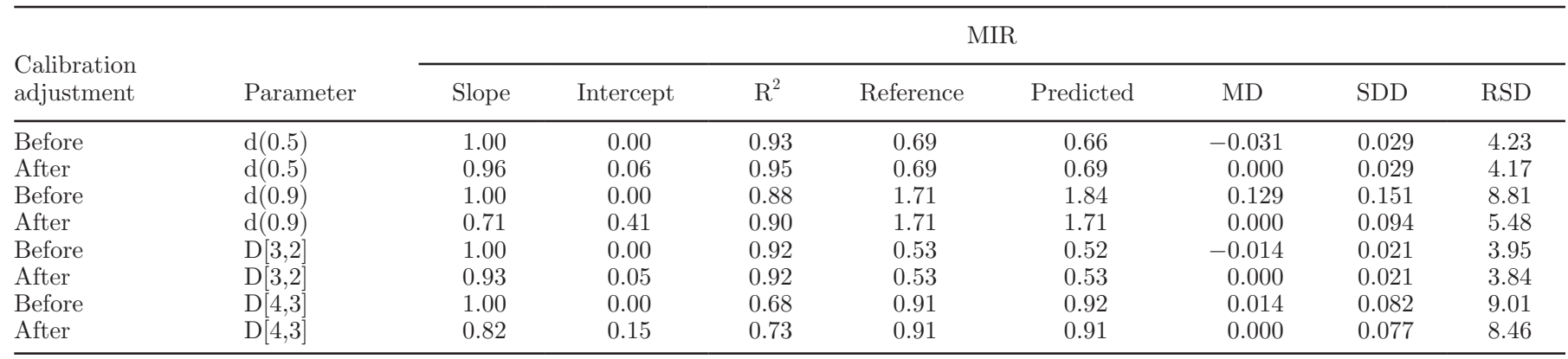

tively. According to Goulden (1964) and Smith et al. (1993), large fat globules can lead to the Christiansen effect, which is a change of the refractive index of milk fat at wavelengths near maximum absorption by the carbonyl and carbon-hydrogen groups. This shifts the apparent wavelength of maximum light absorption to a longer wavelength. The Christiansen effect is observed in Figures 3B and 4B. We concluded that systematic variation in the spectra due to the Christiansen effect enabled the PLS models to predict particle size distribution from the MIR spectra.

\section{What Could be the Cause of the Larger Sample- to-Sample Variation of $d(0.9)$ and $D[4,3]$ ?}

In the model-development phase, the milk in the cuvette and the milk tested by laser light scattering were identical because the homogenization was done with a homogenizer external to the MIR and there was no homogenizer in the MIR flow system. This approach should produce MIR prediction models that would produce accurate results. Both for slope and intercept, adjustment of the model data output and for validation was different because the homogenization step took place in-line within the instrument's flow system, not external to the system. As indicated, the volume of instrument homogenized milk (about 2 drops) in the cuvette is a very small portion of the total milk that passed through the homogenizer during the measurement cycle. For slope and intercept adjustment and for validation, the reference test was conducted on the total volume of milk from the measurement cycle (i.e., many pump strokes), whereas the milk spectra is only from a portion of one pump stroke. It is likely that there is pump stroke-to-pump stroke variation in the homogenization efficiency; thus, in the case of the real-time analysis, random variation exists from pump stroke to pump stroke in the particle size produced by the homogenizer. This would lead to accurate predictions on average of many samples but larger sample-to-sample variation. It is likely that the variation in the particle size distribution produced from one pump stroke to the next will be larger as the homogenizer becomes less efficient (i.e., produces larger particle size). This may be why the larger RSD were observed for the $\mathrm{d}(0.9)$ and $\mathrm{D}[4,3]$, whereas the average $\mathrm{d}(0.9)$ and $\mathrm{D}[4,3]$ for a

Table 3. Comparison of mean of reference values, mean of mid-infrared (MIR) predicted values, mean difference (MD) between MIR predicted and reference values, standard deviation of the differences (SDD) between reference and predicted, and relative standard deviation (RSD) of validation step of the partial least square (PLS) model performance evaluation

\begin{tabular}{lccrrr}
\hline & \multicolumn{5}{c}{ MIR } \\
\cline { 2 - 6 } Parameter $^{1}$ & Reference & Predicted & \multicolumn{1}{c}{ MD } & SDD & \multicolumn{2}{c}{ RSD } \\
\hline $\mathrm{d}(0.5)$ & $0.658^{\mathrm{a}}$ & $0.634^{\mathrm{b}}$ & -0.024 & 0.036 & 5.47 \\
$\mathrm{~d}(0.9)$ & $1.626^{\mathrm{a}}$ & $1.645^{\mathrm{a}}$ & 0.019 & 0.148 & 9.10 \\
$\mathrm{D}[3,2]$ & $0.516^{\mathrm{a}}$ & $0.503^{\mathrm{b}}$ & -0.012 & 0.022 & 4.32 \\
$\mathrm{D}[4,3]$ & $0.868^{\mathrm{a}}$ & $0.838^{\mathrm{b}}$ & -0.029 & 0.110 & 12.67 \\
\hline
\end{tabular}

${ }^{\mathrm{a}, \mathrm{b}}$ Means not sharing a common superscript differ $(P<0.05)$.

${ }^{1}$ Particle size distributions $\mathrm{d}(0.5)$ and $\mathrm{d}(0.9)$, surface volume mean diameter $\mathrm{D}[3,2]$, and volume moment mean diameter $\mathrm{D}[4,3]$. 
large number of validation samples had good agreement of overall mean values (Table 3). This may lead to the decrease in milk fat analytical repeatability reported for less efficient homogenizers (Smith et al., 1994) and may also affect the accuracy of fat predictions by both traditional filter models and PLS prediction models of fat content of milk.

\section{CONCLUSIONS}

Partial least square regression models for predicting the particle size distributions $\mathrm{d}(0.5)$ and $\mathrm{d}(0.9)$, surface volume mean diameter $\mathrm{D}[3,2]$, and volume moment mean diameter $\mathrm{D}[4,3]$ of milk fat globules in homogenized milk from an MIR milk spectra were
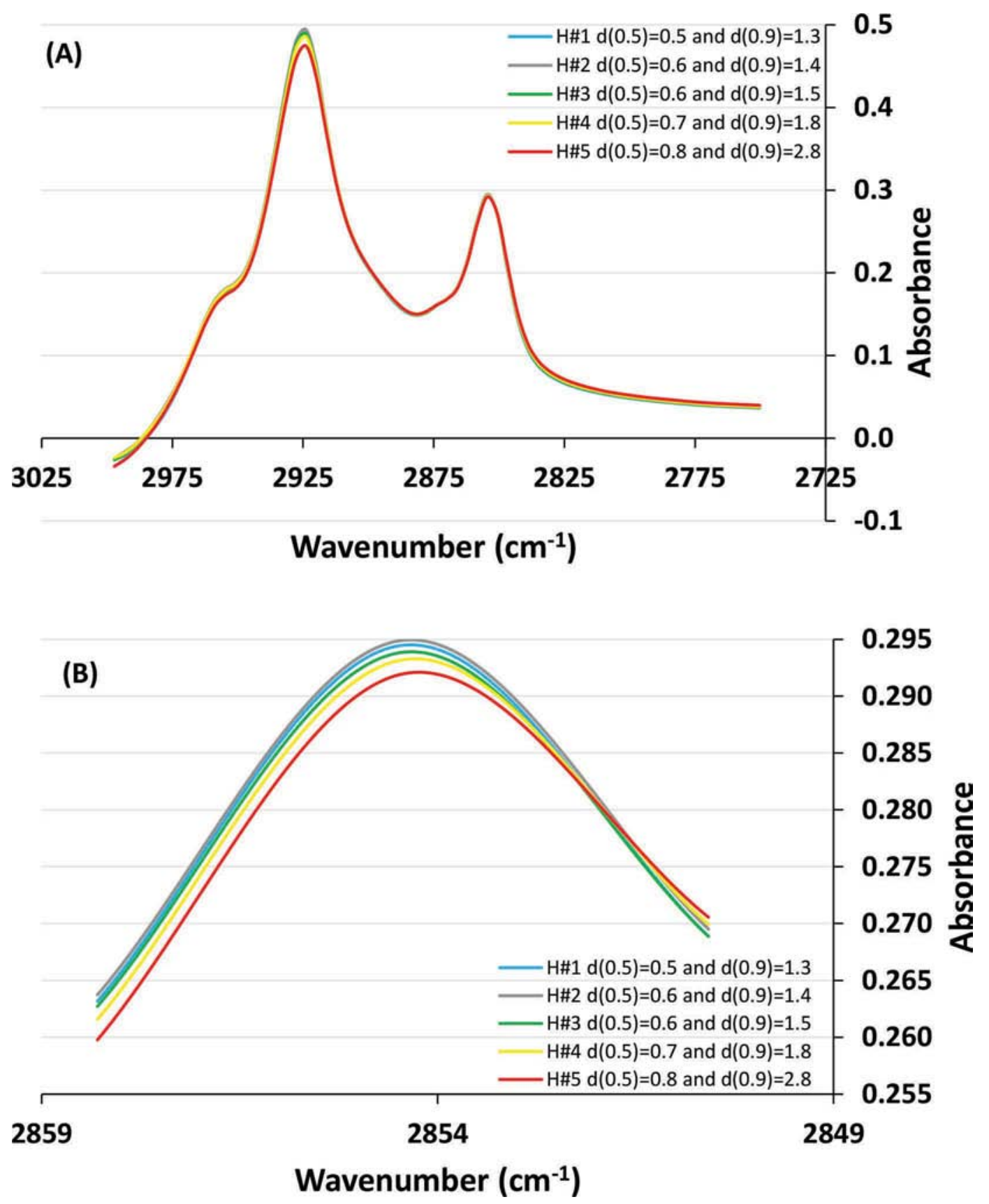

Figure 3. Mid-infrared absorbance spectra plotted as a function of wavenumber $\left(\mathrm{cm}^{-1}\right)$ for sample $12(5 \%$ fat and $2.4 \%$ true protein) of the modified milk set, replicate 1 , homogenized with 5 different homogenizers (H\#1 to H\#5) producing milks with different particle size distributions $\mathrm{d}(0.5)$ and $\mathrm{d}(0.9)$ in spectral region of: (A) 3,000 to 2,750 and (B) 2,860 to 2,850 $\mathrm{cm}^{-1}$. Color version available online. 

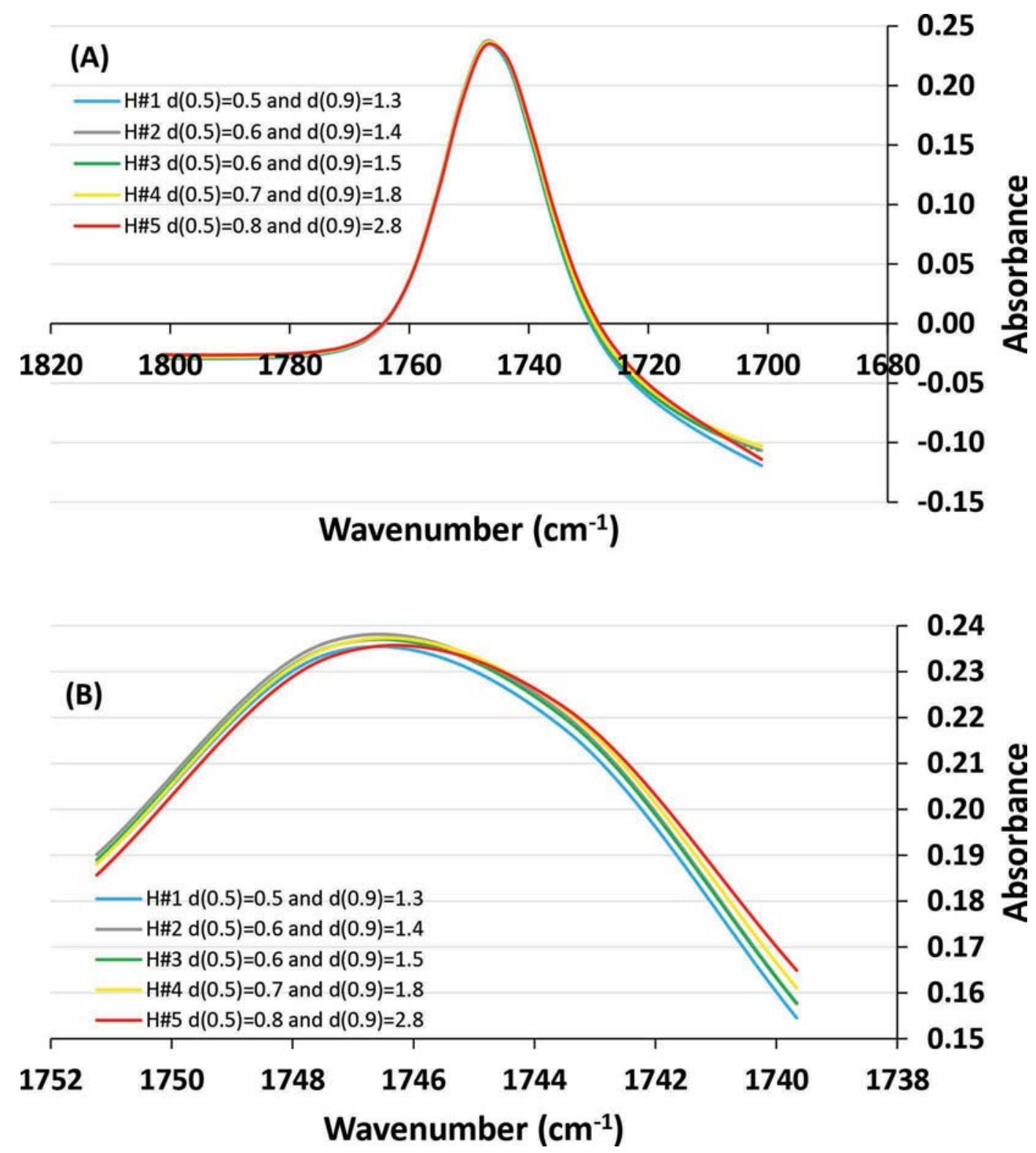

Figure 4. Mid-infrared absorbance spectra plotted as a function of wavenumber $\left(\mathrm{cm}^{-1}\right)$ for sample $12(5 \%$ fat and $2.4 \%$ true protein) of the modified milk set, replicate 1 , homogenized with 5 different homogenizers ( $\mathrm{H} \# 1$ to $\mathrm{H} \# 5$ ) producing milks with different particle size distributions $\mathrm{d}(0.5)$ and $\mathrm{d}(0.9)$ in spectral region of: (A) 1,800 to 1,700 and (B) 1,750 to $1,740 \mathrm{~cm}^{-1}$. Color version available online.

developed and validated. The basis for the ability to model particle size distribution of milk fat emulsions was hypothesized to be the result of the PLS modeling detecting absorbance shifts in MIR spectra of milk fat due to the Christiansen effect. The independent sample validation of particle size prediction methods found more variation in $\mathrm{d}(0.9)$ and $\mathrm{D}[4,3]$ predictions than the $\mathrm{d}(0.5)$ and $\mathrm{D}[3,2]$ predictions relative to laser light-scattering reference values, which may be due to variation in particle size among different pump strokes. The accuracy of the $\mathrm{d}(0.9)$ prediction for routine qual- ity assurance to determine if a homogenizer within an MIR milk analyzer was near the failure level [i.e., d(0.9) $>1.7 \mu \mathrm{m}]$ and needed to be replaced is fit-for-purpose. The daily average particle size performance [i.e., d(0.9)] of a homogenizer based on the mean for the day could be used for monitoring homogenizer performance.

\section{ACKNOWLEDGMENTS}

The authors thank the USDA Federal Milk Markets laboratories of Cleveland, Ohio, Dallas, Texas, and 
Lebanon, New Hampshire, for their collaboration. The authors thank the Northeast Dairy Foods Research Center (Ithaca, NY) and Delta Instruments (Drachten, the Netherlands) for support of this research. The technical assistance of Chassidy Coon, Michelle Billota, and Sara Bova of Cornell University and the service staff of Delta Instruments was greatly appreciated.

\section{REFERENCES}

Adams, M. C., and D. M. Barbano. 2015. A novel statistical approach to detect differences in fat and protein test values among midinfrared spectrophotometers. J. Dairy Sci. 98:4174-4181.

Allen, T. 1990. Particle Size Measurement. 4th ed., Chapman and Hall, London, UK.

AOAC International. 2000. Official Methods of Analysis. 17th ed. AOAC International, Gaithersburg, MD.

Barbano, D. M., and J. L. Clark. 1989. Infrared milk analysis: Challenges for the future. J. Dairy Sci. 72:1627-1636.

Barbano, D. M., and J. M. Lynch. 2006. Major advances in testing of dairy products: Milk component and dairy product attribute testing. J. Dairy Sci. 89:1189-1194.

Barbano, D. M., K. L. Wojciechowski, and J. M. Lynch. 2010. Effect of preservatives on the accuracy of mid-infrared milk components testing. J. Dairy Sci. 93:6000-6011.

Biggs, D. A. 1967. Milk analysis with the infrared milk analyzer. J. Dairy Sci. 50:799-803.

Biggs, D. A., G. Johnsson, and L. O. Sjaunja. 1987. Analysis of fat, protein, lactose and total solids by infrared absorption. Pages 2130 in Monograph on Rapid Indirect Methods for Measurement of the Major Components of Milk. Bull. Int. Dairy Fed. Int. Dairy Fed., Brussels, Belgium.

Goulden, J. D. S. 1961. Quantitative analysis of milk and other emulsions by infrared absorption. Nature 191:905-906.

Goulden, J. D. S. 1964. Analysis of milk by infrared absorption. J. Dairy Res. 31:273-284.

Goulden, J. D. S., and L. W. Phipps. 1964. Factors affecting the fat globule sizes during the homogenization of milk and cream. J. Dairy Res. 31:195-200.

Haaland, D. M., and E. V. Thomas. 1988. Partial least-squares methods for spectral analyses. 1. relation to other quantitative calibration methods and the extraction of qualitative information. Anal. Chem. 60:1193-1202.
Horvath, H. 2009. Gustav Mie and the scattering and absorption of light by particles: Historic developments and basics. J. Quant. Spectrosc. Radiat. Transf. 110:787-799.

International Dairy Federation. 2000. ISO 9622:1999. Whole milk: Determination of milkfat, protein and lactose content-Guidance on the operation of mid-infrared instruments. IDF Standard 141C:2000. Int. Dairy Fed., Brussels, Belgium.

Janik, L. J., J. O. Skjemstad, K. D. Shepherd, and L. R. Spouncer. 2007. The prediction of soil carbon fractions using mid-infraredpartial least square analysis. Aust. J. Soil Res. 45:73-81.

Kaylegian, K. E., G. E. Houghton, J. M. Lynch, J. R. Fleming, and D. M. Barbano. 2006. Calibration of infrared milk analyzers: Modified milk versus producer milk. J. Dairy Sci. 89:2817-2832.

Kaylegian, K. E., J. M. Lynch, J. R. Fleming, and D. M. Barbano. 2009. Influence of fatty acid chain length and unsaturation of midinfrared milk analysis. J. Dairy Sci. 92:2485-2501.

Lynch, J. M., D. M. Barbano, J. R. Fleming, and D. Nicholson. 2004. Component testing, the dairy industry, and AOAC International. Pages 24-28 in Inside Laboratory Management: A Publication of AOAC International, vol. 8. AOAC Int., Gaithersburg, MD.

Lynch, J. M., D. M. Barbano, M. Schweisthal, and J. R. Fleming. 2006. Precalibration evaluation procedures for mid-infrared milk analyzers. J. Dairy Sci. 89:2761-2774.

Phipps, L. W. 1960. A small-capacity laboratory homogenizer. Lab. Pract. 9:313-316.

Phipps, L. W. 1975. The fragmentation of oil drops in emulsions by a high-pressure homogenizer. J. Phys. D Appl. Phys. 8:448-462.

Smith, E. B., D. M. Barbano, and J. M. Lynch. 1993. Performance of homogenizers in infrared milk analyzers: A survey. J. AOAC Int. 76:1033-1041

Smith, E. B., D. M. Barbano, and J. M. Lynch. 1994. Effect of infrared analyzer homogenization efficiency on repeatability of uncorrected fat A and fat B signals. J. AOAC Int. 77:1217-1223.

Smith, E. B., D. M. Barbano, and J. M. Lynch. 1995. Infrared analysis of milk: Effect of homogenizers and optical filter selection on apparent homogenization efficiency and repeatability. J. AOAC Int. $78: 1225-1233$.

Walstra, P., and R. Jenness. 1984. Milk fat globules. Pages 266-269 in Dairy Chemistry and Physics. John Wiley \& Sons, New York, NY.

Williams, P. 2010. The analysis of wheat by near infrared spectroscopy. Pages 359-362 in Applications of Vibrational Spectroscopy in Food Science. Volume 1. Instruments and Fundamental Applications. E. C. Y Li-Chan, P. R. Griffiths, and J. M. Chambers, ed. John Wiley \& Sons, London, UK. 